\title{
EL NUEVO ORDEN CONSTITUCIONAL DE LA REPUBLICA POPULAR CHINA
}

\author{
Por BERNARDO FERNANDEZ PEREZ \\ Universidad de Oviedo
}

\section{INTRODUCCION}

Tras sólo tres años de vigencia, aunque quizás no de eficacia, de la Constitución de 1975, la República Popular China se ha dotado de un nuevo texto constitucional -el tercero en sentido formal de su historiaaprobado en la I Sesión de la V Asamblea Popular Nacional (APN) el 5 de marzo de 1978 (1). La promulgación de esta norma fundamental clausura un largo período de lucha política, iniciada con la Revolución Cultural, y representa la hegemonía de uno de los sectores de la élite política china, la consolidación en el poder de una de las «líneas» en conflicto. La Constitución de 1978 explícita, como se intenta probar en este trabajo, la situación dominante del grupo conocido como "moderado" y de sus tesis, y la derrota del «radical», identificado como «Grupo de Shanghai» (2).

(1) La V Asamblea Popular Nacional estuvo integrada por 3.497 diputados elegidos por las treinta provincias, municipios y regiones autónomas y por el Ejército Popular de Liberación: de ellos, 26,7 por 100 eran obreros; 20,6 por 100 , campesinos; 14,4 por 100 , del EPL; 13,4 por 100 , cuadros revolucionarios; 15 por 100 , intelectuales; 8,9 por 100 , personalidades patriotas, y 1 por 100, chinos de ultramar repatriados. Estuvieron representadas las 54 minorías nacionales. Cfr. Pekin Informa, n. ${ }^{\circ} 11,22$ de marzo de 1978, pág. 39.

(2) El discurso político tiende ahora a presentar los sectores en conflicto de forma simplificada, como el enfrentamiento de la inmensa mayoría contra la conspiración de un reducido grupo, la "banda de los cuatro" en la jerga oficial -Chang Chun-Chiao, Yao Wen-Yuan, Wang Yung-Wen, Chiang-Ching - que no es, en realidad, sino la cabeza visible de un amplio movimiento, según se deduce de la intensa campaña, desarrollada durante 1977 , de reorganiza- 
El enfrentamiento de sectores, su lucha por el poder, supone un intenso debate ideológico entre distintas concepciones del desarrollo económico, social y político durante la construcción del comunismo, más precisamente. durante el período de transición socialista, fase previa a la instauración de la sociedad comunista. La toma del poder por una de las dos "lineas» implica realizar las condiciones de desarrollo implícitas en su concepción y fijarlas minuciosamente, junto con las perspectivas de evolución futura, en un nuevo orden juridico-constitucional expresión del orden político instaurado. La disputa dirime, pues, un interesante dilema acerca de las características organizativas de la fase de transición, que el examen de la Constitución va a permitir poner de manifiesto.

El debate se constituye sobre un campo conceptual que parece aceptado unánimemente por los grupos ideológicos en conflicto: la crítica al modelo soviético de transición al comunismo, a las tesis de la desaparición paulatina de la lucha de clases durante la fase socialista y, por consiguiente, la negación china del carácter ocioso, de la inutilidad de la dictadura del proletariado como forma estatal de todo el período de transición. A la extinción de la dictadura del proletariado, al unificarse el pueblo soviético tras las transformaciones operadas con la socialización de la propiedad de los medios de producción, sucede, en la doctrina soviética, el «Estado de todo el pueblo», forma estatal que organiza el segundo periodo de transición, el que media entre el socialismo maduro y la fase comunista. Frente a las tesis soviéticas, los comunistas chinos conciben toda la etapa socialista como un período de transición en el que la transformación de la estructura de la propiedad no supone la desaparición automática de las clases sociales y de la lucha de clases, ni de las contradicciones entre las relaciones de producción y las fuerzas productivas o entre superestructura y base aconómica. Consecuentemente, al definir la fase socialista íntegra como un periodo de transición

ción de la élite politica en la estructura local del Partido Comunista, y del desplazamiento, y en ocasiones ejecución, de los partidarios de la tendencia "radical». Cfr. Keesing's Contemporary Archives, 1977, págs. 28718-9, que detalla los cambios operados en 21 provincias y regiones autónomas.

Una excelente síntesis de las vicisitudes de la lucha política en los últimos años, en Keesing's..., 1975, págs. 26965-9; 1976, págs. 27667-72 y 27805-7; 1977, págs. 28205-14 y 28717-25. También son útiles los artículos de K. S. KAROL, «De Teng a Teng. Tres años de lucha política en China" y «De regreso a China (11 de Febrero de 1978)», incluidos en Ch. BetTelheim y otros, China después de Mao. Materiales, análisis, documentos sobre la lucha politica en la transición socialista, Barcelona, El Viejo Topo, 1978. 
en el que subsiste la lucha de clases, se postula el carácter necesario de la dictadura del proletariado (3).

La coincidencia de ambas corrientes en la critica al modelo soviético, y en la defensa de la dictadura del proletariado durante toda la fase socialista, queda de manifiesto en varios textos de componentes del «Grupo de Shanghaì, tales La dictadura integral sobre la burguesia, de Chang Chun-Chiao, - Acerca de la base social de la camarilla autipartido de Lin Piao, de Ya Wen-Yuan; o explícitamente en el Informe politico ante el XI Congreso Nacional del Partido Comunista Chino, presentado en agosto de 1977 por el actual presidente del partido y de su comisión de asuntos militares, primer ministro y comandante en jefe de las fuerzas armadas, Hua Kuo-Feng:

«...El presidente Mao, valiéndose de la ley dialéctica materialista de la unidad de los contrarios para examinar y analizar la sociedad socialista, enseña que la sociedad socialista cubre una etapa histórica bastante larga y que, durante la etapa histórica del socialismo, siempre existen clases, contradicciones de clase y lucha de clases, existe el peligro de restauración capitalista y existe la amenaza de subversión y agresión por parte del imperialismo y del socialimperialismo. Por eso, en esta etapa histórica, se hace necesario persistir en la lucha del proletariado contra la burguesia, en la dictadura del proletariado sobre la burguesía y en la continuación de la revolución bajo la dictadura del proletariado. Así, esta teoria ha hecho añicos, definitivamente, falacias revisionistas como la "teoria de la extinción de la lucha de clases" y las falacias del "Partido de todo el Pueblo" y del "Estado de todo el pueblo"» (4).

Sin embargo, esta coincidencia se reduce exclusivamente a la forma

(3) La doctrina del bloque soviético acerca de la periodificación del proceso de edificación del comunismo ha sido expuesta entre nosotros por Manuel B. Garcia ALVAREZ, Construcción del comunismo y Constitución, León, Colegio Universitario, 1978, págs. 13 y ss. La concepción china de la dictadura del proletariado puede verse en TSIEN TCHE-HaO, La Chine, París, L.G.D.J., 1976, págs. 191-230. Una sucinta exposición de la crítica maoísta al modelo soviético, en DAVID LANE, The socialist industrial state, Towards a political sociology of state socialism, LONDON, Allen and Unwin, 1976, págs. 31-35.

(4) Undicimo Congreso Nacional del Partido Comunista de China (Documentos), Pekín, Ediciones en Lenguas Extranjeras, 1977, págs. 29-30. El texto de CHANG CHUN-CHIAO; püblicado originalmente en Bandera Roja, abril de 1975, puede verse en $\mathrm{CH}$. BETtELHElM y otros, op. cit., págs. 98-108. El de YaO Wen-YuAN, del número de Bandera Roja, de mázo de 1975, en VARios, China: La lucha por el poder, Barcelona, E. Ricou, 1978, págs. 271-85, obra que también recoge el artículo anterior en págs. 287 y ss. Versiones resumidas de ambos textos, en Keesing's, 1976, págs. 276-689. 
estatal de organización de la fase de transición, a la aceptación de una estructura genérica del poder político, la dictadura del proletariado, pero no alcanza al modelo de gestión, al modelo de desarrollo de la sociedad socialista en la fase de transición. La discrepancia se genera en el orden de las prioridades, según se privilegie el desarrollo de la base económica, en la perspectiva de una acumulación socialista que se juzga necesaria, o el de la superestructura; según se articulen conceptualmente las relaciones entre fuerzas productivas y relaciones de producción, o se valore el carácter preferente o no de la transformación radical de las relaciones sociales en el conjunto de la formación social.

Ambas tendencias - «radicales» y «moderados»- comparten el programa, anunciado por Chou En-Lai en el Informe sobre la labor del gobierno ante la IV APN en 1975(5), que proyecta construir un sistema económico e industrial relativamente completo e independiente antes de 1980, y llevar a cabo antes de finales del siglo una profunda modernización de la agricultura, la industria, defensa nacional y ciencia y tecnología, las llamadas "Cuatro modernizaciones». Pero las diferencias de criterio surgen en el momento de articular el modelo de gestión preciso para realizar tan ambicioso programa; discrepancias que, por otro lado, no se comprenden sin referir el conjunto de problemas implicado en esta fase de construcción del socialismo a la crítica que China hace del modelo soviético. En otros términos, el debate se origina cuando, al desarrollar este programa, se tiene presente la $n$ scesidad de eludir los que el comunismo chino considera errores, y consiguiente degeneración del socialismo, soviéticos: una acumulación socialista acelerada que privilegia el desarrollo de la industria pesada en perjuicio de la ligera, de la producción de bienes de consumo y de los intereses del campesinado; proclamación de la inexistencia de clases sociales tras la sola socialización (6) de la propiedad de los medios de producción, sin atender a la persistencia de caracteres capitalistas en las relaciones de producción, si no se posibilita su transformación radical. En este contexto de crítica del modelo soviético deben incardinarse las polémicas sobre los modelos de dirección en el seno de las unidades de producción -desarrollo de comités revolucionarios, grupos de gestión, etc., frente a la dirección

(5) Puede verse en Documentos de la I Sesión de la IV Asamblea Popular Nacional de la República Popular China. Pekín, Ediciones en Lenguas Extranjeras, 1975, págs. 47-66.

(6) Por "socialización» se entiende aquí, como parece se ha entendido en la URSS, supresión de la propiedad privada de los medios de producción. Para una discusión de las diferencias entre «nacionalización» y «socialización», entre "public ownership» y «social ownership» y sus consecuencias, Wlodzimierz Brus, Socialist ownership and political systems, London-Bosto, Routledg and Kegan, 1975. 
única-; fomento del igualitarismo en la distribución de la producción social, frente a la persistencia de incentivos materiales - primas, salarios por pieza...-; el ataque a los reglamentos de organización interior de las fábricas; el debate sobre la persistencia del «derecho burgués»; la consideración de la ley del valor en el intercambio; el mantenimiento o no de cierta propiedad privada en el sector agrario; la posibilidad de producciones agrícolas subsidiarias y de su intercambio en el mercado, etc.

$Y$ así, pese a la coincidencia inicial en la necesidad de un importante cambio cuantitativo en el proceso de producción, el enfrentamiento entre «radicales» $y$ «moderados» se origina en el momento de conjugar dicho cambio con la revolución, puesto que previamente se ha descartado que ésta se realice con la sola abolición de la propiedad privada de los medios de producción; en el momento, en fin, en que deben articularse producción y revolución, política y economía.

Para el Grupo de Shanghai, el riesgo de que los factores residuales de economía capitalista en las relaciones de producción provoquen una «restauración del capitalismo» exige el reforzamiento de la «política proletaria» en todo el proceso, la necesidad de privilegiar la dictadura del proletariado -elemento político- sobre el desarrollo económico, sobre el desarrollo de las fuerzas productivas, y de instalar en el poder «la política» y no "el beneficio». Consecuentemente, la consigna de Mao de perseverar en la dictadura del proletariado, imponer el orden y la estabilidad e incrementar la producción, se interpreta valorando la dictadura del proletariado como el elemento clave al que deben supeditarse los otros dos. El desarrollo económico tiene que someterse y condicionarse, en última instancia, a la implantación de unas relaciones de producción con el mínimo contenids capitalista: las primas y estimulos materiales el principio socialista de distribución, "a cada uno según su trabajo», en suma- deben desaparecer radicalmente; los restos de propiedad privada en el sector agrario - explotaciones familiares, intercambio de producciones marginales en el mercado...-, ser abolidos; las escalas salariales - de ocho grados entre los trabajadores, quince entre los técnicos y veinticinco entre funcionarios y cuadros del partido-, estrecharse drásticamente hasta llegar a la igualdad de salario. En otro orden, la dictadura del proletariado debe ser omnímoda sobre toda manifestación: superestructural (art. 12 de la Constitución de 1975), pues la lucha de clases se extiende al ámbito cultural — no hay ciencia ni arte neutrales-y a la enseñanza; y el «derecho burgués», por innecesario y, a la postre, residuo capitalista, suprimido, concepción que subyace en la Constitución de 1975.

A la iniciativa del Grupo de Shanghai, y como fortalecimiento y expansión 
de su línea ideológica, se debe el desarrollo de campañas como la comenzada en 1973 contra Confucio y Lin Piao; la de fomento del igualatarismo, agudizada en el verano de 1974 y causa de importantes conflictos, como los generados entre los ferroviarios en Hangchow; o las campañas contra el "derecho burgués» y los capitulacionistas, o la comenzada en febrero de 1975 para el estudio de la dictadura del proletariado.

El sector "moderado» - en el que Hua Kuo-Feng personificó inicialmente una tendencia intermedia entre el radicalismo del Grupo de Shanghai y el pragmatismo o economicismo de Teng Shiao-Ping, para solidarizarse finalmente con este último- postula un desarrollo simultáneo de la base económica y de la superestructura, pero privilegiando en última instancia el desarrollo de las fuerzas productivas haciendo depender el desarrollo del socialismo del progreso económico. Así se formula, como secuencia concatenada de necesidades, por Hua Kuo-Feng en el Informe politico ante el XI Congreso Nacional del Partido Comunista Chino, en agosto de 1977:

«El Presidente Mao... señala que, en la sociedad socialista, hay consonancia y contradicción simultáneas entre las relaciones de producción y las fuerzas productivas y entre la superestructura y la base económica. Todo aquello que en las relaciones de producción no corresponda a las fuerzas productivas, así como todo aquello que en la superestructura no concuerde con la base económica, entorpece el desarrollo de las fuerzas productivas. (...) Es necesario realizar la innovación y la revolución técnicas y desarrollar rápidamente las fuerzas productivas, para dotar al sistema socialista de una base material cada vez más poderosa e impulsar el desarrollo y las transformaciones de las relaciones de producción y la superestructura. (...) El desarrollo de la economía socialista constituye una de las tareas fundamentales de la dictadura del proletariado. Desarrollar rápidamente las fuerzas productivas es un requerimiento para fortalecer la base material de dicha dictadura, (...) para preparar las condiciones materiales que permitan disminuir gradualmente las tres diferencias principales, con miras a pasar a la sociedad comunista. Las fuerzas productivas son el factor más revolucionario. La necesidad de continuar la revolución en los dominios de la superestructura y las relaciones de producción bajo la dictadura del proletariado es, a fin de cuentas, una exigencia del desarrollo de las fuerzas productivas.» (sub. B.F.P.) (7).

(7) Undécimo Congreso..., op. cit., págs. 30-1 y 92-3. 
De nuevo, y de modo aún más nítido, lo explicitará Ye Chien-Ying en el Informe sobre la reforma de la Constitución:

«Si no ponemos en pleno juego la superioridad del sistema socialista para acelerar el desarrollo de las fuerzas productivas sociales y estructurar gradualmente el sistema socialista de nuestro país sobre una poderosa base material de gran producción moderna, no seremos capaces de frenar eficazmente el crecimiento de las fuerzas capitalistas y, lo que es más, nos veremos colocados en una situación de vulnerabilidad ante las eventuales agresiones del socialimperialismo y el imperialismo. (...) Una condición importante para la victoria del socialismo sobre el capitalismo (es) desarrollar la economia nacional a un ritmo acelerado y aumentar constantemente las fuerzas productivas sociales.» (8).

Esta tendencia parece optar, en definitiva, por un "desarrollo a gran velocidad de las fuerzas productivas» frente a la preferencia del Grupo de Shanghai "por un lento ritmo socialista", y formula con claridad la necesidad de una acumulación socialista acelerada. El importante informe sobre la labor de Gobierno hecho por Hua Kuo-Feng ante la APN en enero de 1978 así lo explicita. Con esa perspectiva, en él se proponen una movilización de toda la naçión para desarrollar la agricultura, elevando el rendimiento por unidad de superficie, mecanizando las explotaciones, permitiendo a los comuneros el cultivo de una pequeña cantidad de tierra a título personal y dedicarse a actividades secundarias, autorizando el «comercio legítimo en las ferias y mercados»; un intenso desarrollo de la industria y del comercio exterior. Estos objetivos son inalcanzables sin una planifica-

(8) Documentos de la I Sesión de la V Asamblea Popular Nacional de la República Popular China, Pekín, Ediciones en Lenguas Extranjeras, 1978, págs. 183-4 y 209-10. El «Informe» ha sido también publicado en Pekín Informa, n. ${ }^{\circ} 11,22$ de marzo de 1978, págs. 17-31. El Diario del Pueblo, 1 de noviembre de 1976 (Apud Keesing's, 1977, pág. 28208), declaraba, para evitar las criticas anteriores del Grupo de Shanghai y buscando disociar el sector Hua Kuo-Feng del de Teng Shiao-Ping: «La teoria de las fuerzas productivas es una teoria revisionista que exagera unilateralmente el papel decisivo de las fuerzas productivas, pero niega la poderosa reacción de las relaciones de producción sobre aquéllas. (...) Nos hemos opuesto a la teoría de las fuerzas productivas tanto en el pasado, como en el presente, y nos opondremos en el futuro; pero ello no puede ser interpretado como oposición al incremento de la producción. La «banda de los cuatro" confundió deliberadamente los dos conceptos y equiparó la teoria de las fuerzas productivas al esfuerzo para estimular la producción; contrapuso la revolución a la producción, la politica a la economía, la lucha de clases a la lucha por la producción y la dictadura del proletariado a la construcción del socialismom. 
ción unificada, aunque con iniciativa tanto de las autoridades centrales como de las locales; si no se establece un «estricto sistema de responsabilidad para los cuadros dirigentes» o no se implanta un "sistema de división del trabajo y de responsabilidad personal del director» en las unidades de producción; si no se combina "el estímulo moral con el material» y se refuerza "en mayor grado el sistema legal socialista", preservando elementos del "derecho burgués» porque "contribuyen a proteger y desarrollar las fuerzas productivas». Sin estas condiciones, y si no «se entrega al Estado una creciente suma de ganancias, será imposible un desarrollo sostenido y acelerado de la economía nacional»; por otro lado, sin utilizar la «ley del valor» ni "estudiar los términos de intercambio entre los productos...» es imposible la acumulación de fondos para el Estado.

El desarrollo económico acelerado se vincula, además, al progreso científico y técnico, por lo que deben liberalizarse todas las manifestaciones del arte y la cultura, y fomentar intensamente la investigación cientifica y la especialización técnica, reformando el sistema educativo, y poniendo «en pleno juego el papel de los intelectuales (que) tiene gran importancia (tanto) para acelerar el desarrollo de la ciencia y la educación y la cultura com para construir un poderoso país socialista moderno" (9). Ante la dictadura omnimoda del proletariado sobre las manifestaciones culturales, Teng ShiaoPing formulará alegóricamente la neutralidad de la ciencia: « ¿Qué importa que el gato sea negro o blanco si captura ratones?».

Pero lo que no resulta neutral ni indiferente es la divergencia de concepciones ante el conjunto de problemas relativos a la fase de transición. Las discrepancias afectan a la propia formulación de la dictadura del proletariado, estrechando lo que inicialmente se afirmaba como campo conceptual de coincidencia de ambas tendencias, la postulación común de la necesidad de la dictadura del proletariado. Mientras el sector «radical» utiliza estrictamente el término "dictadura del proletariado», el grupo actualmente dominante parece iniciar el uso, siquiera incidental - si no en el texto constitucional, sí en documentos complementarios como el Informe sobre la reforma de la Constitución - de un término, recuperado del preámbulo de la Constitución de 1954 y avalado con citas del Presidente Mao (10), "dictadura democrática popular"». Ambas categorías presentan diferencias de matiz de gran relevancia, fundamentalmente en cuanto a su sustancia de clase: para los "radicales», a cuya inspiración parece deberse la Constitución de 1975, el sujeto de la dictadura es el proletariado, cuyo núcleo dirigente, el Partido Comunista

(9) Documentos de la $V A P N \ldots$, págs. 44, 52 pasim.

(10) Ibídem, págs. 185-7. 


\section{ARTICULOS}

Chino (P.C.Ch.), adquiere un estatus supraestatal; en la concepción moderada el sujeto es el "pueblo", conjunto de distintas fuerzas sociales organizadas en el Frente Unico Revolucionario bajo la hegemonia del PCCh, cuyo estatus varía notablemente -si no en los estatutos del partido, sí en la Constitución-, ya que aunque el artículo 2 siga fijando su papel rector del Estado, ya no dirige el órgano supremo del poder estatal, la APN.

Las tesis del grupo dominante (11) recuerdan, en no pocas opciones, el modelo soviético. ¿Estamos, pues, ante una convergencia objetiva de procedimientos en la construcción del comunismo, en la gestión de la fase socialista? ¿Finaliza así la especifidad del modelo chino? En este sentido, y aunque se exhuman textos de Mao que invitan a emular los ejemplos del pueblo soviético, sus logros, pero no los de su «camarilla revisionista dirigente» (12), la resolución de persistir en un modelo que eluda los que se estiman errores soviéticos se deduce de la recuperación de un texto de Mao de gran importancia: Sobre las diez grandes relaciones, de 1956 - - reeditado por Hua Kuo-Feng, y al que parece se han añadido, precisamente, referencias a la URSS, como contraejemplos-, y cuyo significado no es momento ahora de comentar. El futuro próximo revelará si se reproduce el modelo soviético o se superan sus inconvenientes, tras una serie de fenómenos - Gran Salto, Revolución Cultural- cuyas experiencias no pueden dejar de incidir en el proyecto chino (13).

(11) Los últimos acontecimientos impiden calificar la élite dirigente china de «utópica», por contraposición a "pragmática», como hace, siguiendo a LowentHal, David LANE, op. cit., págs. 137-42.

(12) Véase el «Discurso del Presidente Mao Tsetung ante la Conferencia ampliada de trabajo convocada por el Comité Central del PCCh», el 30 de enero de 1962, en Pekin lnforma, n. ${ }^{\circ} 27,12$ de julio de 1978, pág. 20.

(13) Acerca de los problemas teóricos aquí sólo insinuados, es útil y muy sugestivo, el artículo de Rossana Rossanda, "El comunismo dificil», en Ch. Bettelheim y otros, op. cit., págs. 9-28; en esta misma obra (págs. 69-77) se incluye una "Nota a las 'diez grandes relaciones'» de Bettelheim. Este autor ha tomado claramente posición a favor del Grupo de Shanghai en una carta, suficientemente difundida, de dimisión como presidente de la Asociación de Amistad Franco-China en mayo de 1977; en su artículo "China hoy: Cambios políticos y lucha de clases (primera parte)", Revista Mensual/Monthly y Review, vol. I, n. ${ }^{\circ}$ 12, junio de 1978, págs. 51-78 argumenta su actitud. Resulta provechosa, no obstante, una lectura comparada de este artículo y el postfacio de Idem, Revolution culturelle et organisation industrielle en Chine, $\mathrm{Pa}-$ ris, Maspero, 1973 (existe traducción española en Siglo XXi). También entre nosotros se han iniciado las solidaridades con el Grupo de Shanghai y los ataques a «los vientos derechistas»: véase el prólogo de José M. Vidal VILla a la obra colectiva China..., cit., págs. 7-15. 


\section{EXAMEN COMPARADO DE LAS CONSTITUCIONES DE 1975 Y 1978. (14)}

La lucha politica y el debate ideológico tienen un singular ámbito de formulación, la Constitución, cuyo análisis permite clarificar los antagonismos - no se comprende sin ellos-y confirmar las tendencias ideológicas dominantes en la actualidad, asi como las líneas de evolución en el futuro (15).

A. La Constitución de 1978 conserva la misma estructura -un Preámbulo y cuatro capítulos- que la de 1975, y carece igualmente de capítulo alguno dedicado a la reforma constitucional, que encomienda (art. 22,1), sin procedimiento agravado, a la APN, por lo que se configura como flexible. Es de extensión media -60 artículos- entre la extraordinariamente breve -30 artículos- de 1975, y los 106 de la de 1954.

(14) La versión española de la Constitución de 1978 y documentos complementarios, en Documentos de la $V$ Asamblea..., cit. También puede verse, junto con el «Informe sobre la reforma de la Constitución», en Pekín Informa, n. ${ }^{\circ} 11,22$ de marzo de 1978, págs. 5-31. La Constitución de 1975, en Documentos de la IV asamblea..., cit., págs. 5-30. Las referencias que se hagan a la Constitución de 1954 lo son de su versión francesa publicada en Informations Constitucionnelles et parlamentaires, $3^{e}$ série, n. ${ }^{\circ} 20$, $1^{\text {er }}$ Novembre 1954, págs. 133-155. Sobre la Constitución de 1975 puede verse, Paolo BisCarett, La Repubblica Popolare Cinese. Un «modello" nuovo di ordinamento statale socialista (Costituzione del 17 gennaio 1975), Milán, Dott. A. Giuffré, 1977, con una rica bibliografia en notas a pie de página y las constituciores de 1954 y 1975 como apéndices. Entre nosotros, Manuel B. García Alvarez, Textos constitucionales Socialistas. Introducción y comentarios, León, Colegio Universitario, 1977, págs. 309-318; MANUEl Marin Arias, "La nueva Constitución de la República Popular China», en Revista de Derecho Público, n. ${ }^{\circ}$ 59, mayo-junio de 1975, págs. 277-288; también, aunque de manera incidental, E. Gomariz, "Bettelheim y la organización industrial en China», en Zona Abierta, n. ${ }^{\circ} 6,1976$, págs. 37 y ss.; Idem, "China y las estructuras políticas de transición», Ibidem, n. ${ }^{\circ} 8,1976$, págs. 84 y ss.; Colectivo INÉS GALÁN, «Notas sobre la organización política en China», Ibídem, n. ${ }^{\circ} 8,1976$, págs. 74 y ss.; José Manuel Valles, China contra Confucio y Lin Piao, Madrid, Ricardo Aguilera, 1975. Quizás las mejores obras sobre la estructura institucional de la RPCh sean las de TSIEN TCHEHAO, La Republique Populaire de Chine. Droit Constitutionnel et institutions, París, L.G.D.J., 1970 y La Chine, op. cit.

(15) El abandono de la concepción constitucional estalinista en el conjunto de estados socialistas es un hecho puesto de relieve por M. B. García Alvarez, Construcción..., op. cit., págs. 63 y ss., y refiriéndose en concreto a la República Popular China, en Textos..., op. cit., pág. 310. También, aunque aludiendo sólo a los estados socialistas europeos, Robert Charvin, Les états socialistes européens. (Institutions et vie politique), Paris, Dalloz, 1975, págs. 226-9. La vigencia en China del concepto de "constitución balance" y no "programa" en el momento de la elaboración del texto constitucional de 1954, en TSIEN TCHE-HAO, La Republique..., op. cit., pág. 23: «Les théoriciens chinois... expliquent également que la constitution est la conclusion générale de la lutte des classes, le moyen par lequel la classe victorieuse protége son pouvoir et le consolide par la légalisation tandis que le Programme Commun dresse une liste des objectifs vers lesquels on doit tendrem. 
El Preámbulo alude, aunque de forma vaga, a una cierta periodificación de la fase socialista en razón del desarrollo económico alcanzado - pues en el orden político está definida por la permanencia de la dictadura del proletariado como forma estatal-: «La dictadura proletaria de nuestro país se ha consolidado y fortalecido, y China se ha convertido en un pais con una prosperidad inicial»; y tras constitucionalizar el final de la «Primera Revolución Cultural Proletaria», se declara que la "revolución y la construcción socialistas de nuestro país ha entrado en un nuevo periodo de desarrollo" (subrayado, B.F.P.). La nueva fase es el período de realización de las ya citadas "cuatro modernizaciones» que deberán lograrse a un "ritmo relativamente acelerado». La vía política de realización es la dictadura del proletariado, en la que debe consolidarse y desarrollarse el Frente Unico Revolucionario, bajo la dirección del P.C.Ch., Frente cuya composición, a diferencia de lo que ocurría en el texto de 1975, es ahora especificada: intelectualidad y otras masas trabajadoras, partidos democráticos patrióticos, personalidades patriotas, ciudadanos de Taiwan, Hong-Kong y Macao, chinos de ultramar. El Preámbulo, en el que se ha introducido la declaración de que Taiwan es «territorio sagrado» de China, finaliza con unas directrices de política internacional -quizás el orden más estable en su orientación pese al proceso de lucha política- entre las que son novedad la mención expresa de la teoría de los tres mundos y el propósito de organizar un Frente Unico internacional, forma organizativa del internacionalismo proletario, que se oponga a las superpotencias (entiéndase la URSS y EEUU).

B. En el capitulo I, "Principios generales», se conservan la definición de la RPCh como Estado socialista de dictadura del proletariado (art. 1); la función dirigente que el P.C.Ch., como vanguardia de la clase obrera, ejerce sobre el Estado; los principios de soberanía popular, unidad del poder y, de modo mucho más explícito que en el texto de 1975, el de división funcional del trabajo, al distinguir órganos del poder estatal - centrales y locales-, del Gobierno popular o administración del Estado, Tribunales y Procuratura, entre los que rige el principio de centralismo democrático $y$, se infiere, el de doble dependencia (arts. 3 y concordantes); se confirman, asimismo, el carácter de Estado multinacional con garantía de autonomía regional «en todas las zonas donde alguna minoria nacional viva en compacta unidad" (idéntica redacción que el art. 3 de la Constitución de 1954), y la igualdad de todas las nacionalidades, recuperándose la prohibición de discriminar $\mathbf{u}$ oprimir cualquier nacionalidad que, recogida en la Constitución de 1954, había sido suprimida en 1975 (art. 4).

Las modificaciones más relevantes en este capítulo son:

1. Redefinición de sectores económicos. Declarando como existentes 
dos únicas formas de propiedad sobre los medios de producción (16), la socialista de todo el pueblo y la colectiva socialista de las masas trabajadoras, los artículos 6 y 7 constituyen dos grandes sectores de la economía, a) el estatal, configurado sobre la propiedad socialista de todo el pueblo, que se extiende ahora a "otros recursos marítimos» —en consonancia, quizá, con la tendencia generalizada a proteger una zona económica exclusiva de pesca- y «terrestres», y estimado «fuerza dirigente de la economía nacional»; b) el de la comuna popular rural, articulado sobre la propiedad colectiva socialista de las masas trabajadoras. Mas debe ponerse de relieve, como modificación de considerable importancia, que la comuna popular ya no es definida (art. 7 de la C.1975) como organización que fusiona el poder de base y la administración económica, definición reservada ahora para sus órganos, para sus instituciones políticas, las asambleas populares locales y comités revolucionarios (art. 34). En este sector económico, la propiedad se organiza en tres niveles, de comuna, brigada de producción y equipo de producción —entidad básica de contabilidad, aunque se prevé que puedan pasar a serlo, donde y cuando las condiciones estén maduras, las brigadas de producción (17).

2. Constitucionalización de la necesidad del crecimiento de las fuerzas productivas, desarrollando la economía a ritmo acelerado y con planificación única, aunque armonizando la iniciativa central con la local y el desarrollo de la agricultura y la industria. Para alcanzar este objetivo, se constitucionaliza el principio socialista de distribución, así como la combinación de los estímulos morales con los incentivos materiales (art. 10); se potencia el desarrollo científico, técnico y educativo (arts. 12 y 13), y se liberaliza - pese a la posición dirigente del marxismo- leninismo - pensamiento Mao Tsetung - la cultura socialista (art. 14), ya que en este orden el Estado aplica la política de «que se abran cien flores y que compitan cien escuelas»

(16) La Constitución sólo reconoce la existencia de esas formas de propiedad sobre los medios de producción - la propiedad personal, garantizada en el artículo 9, no puede tener por objeto más que rentas de trabajo, casa, vivienda y otros medios de subsistencia - con lo que se niega la persistencia marginal de propiedad privada, reconocida como subsistente por CHANG Chun-Chiao, «La dictadura integral sobre la burguesía», en Ch. BetTelheim y otros, op. cit., págs. 100-1.

(17) Esta redefinición de sectores económicos recoge la sistemática de los arts. 6 y 7 de la Constitución de 1954, aunque consolidando las transformaciones realizadas en la estructura de la propiedad y sustituyendo el alli denominado «sector cooperativo" por el «sector económico de la comuna popular rural», con lo que se ratifica la constitucionalización de esta organización creada en 1968. Sobre la comuna popular, Tsien TChe-H^o, La Republique..., op. cit., págs. 381-414; especificamente sobre la rural, IDEM, La Chine, op. cit., págs. 477-83. 
(art. 14,2) y se declara el derecho a la libre investigación científica y de creación literaria, artística u otra actividad cultural (art. 52), habiéndose suprimido el apartado $1 .^{\circ}$ del art. 12 de la Constitución de $1975-$ «El proletariado debe ejercer una dictadura omnimoda sobre la burguesía en la superestructura, incluidos todos los dominios culturales»- y matizado que "todas las instituciones culturales» deben ponerse al servicio del socialismo y no de la "política proletaria», según declaraba el apartado $2 .^{\circ}$ del citado artículo. En esta línea proyectada de las "cuatro odernizaciones», la Constitución declara inviolables los bienes públicos socialistas, y encomienda al Estado la protección del medio ambiente, los recursos naturales y la lucha contra la contaminación, precepto similar, entre otros, al art. 18 de la Constitución soviética de 1977. Asimismo coincidiendo con la Constitución de 1975, se autoriza el trabajo individual no agrícola siempre que no se explote a otros, y se reconoce el «huerto familiar», la posesión personal de un reducido número de cabezas de ganado y la posibilidad de dedicarse a «limitadas ocupaciones secundarias» (18).

3. Introducción del principio de «democracia socialista». En contraposición al silencio que sobre este tema guardaba la Constitución de 1975 - dificilmente su art. 13 puede considerarse correlativo, cuando sólo contemplaba el derecho de plena manifestación de las ideas, recurriendo a debates, dazibaos y otros medios dentro del capitulo de "Principios Generales», materias que ahora se regulan en el art. 45 del capítulo III, «Derechos y deberes fundamentales de los ciudadanos»-, la nueva Constitución dedica un artículo a declarar que «El Estado se atiene al principio de la democracia socialista, y asegura que el pueblo participe en la administración de los asuntos estatales y en el manejo de los asuntos económicos, culturales, y supervise los organismos del Estado y su personal» (art. 17). Se confirma la necesidad de que los organismos del Estado deben mantener «contacto estrecho y permanente con las masas populares, apoyarse en ellas, atender sus opiniones, combatir el burocratismo", y los funcionarios, estudiar el marxismo-leninismo-pensamiento Mao Tsetung y perfeccionar su trabajo, aunque se omite que deba colocarse «firmemente al mando la política proletaria» (arts. 15 y 16). Subsiste la privación de derechos políticos de ciertas capas sociales - terratenientes;

(18) El Diario del Pueblo (Apud Keesing's, 1977, pág. 28209) acusaba al Grupo de Shanghai» de haber querido abolir este tipo de actividades, así como los mercados rurales. Las nuevas tendencias en materia educativa, científica y cultural puede verse en la información que sobre las Conferencias Nacionales de "las Ciencias» y el "Trabajo Educacional" publica Pekin Informa, n. ${ }^{\circ}$ 12, 29 de marzo de $1978 ; n .^{\circ} 13,5$ de abril de $1978 ; n .^{\circ} 18,10$ de mayo de $1978 ; n .^{\circ} 19,17$ de mayo de 1978. 
campesinos ricos, capitalistas reaccionarios-y se añade (art. 18) como actividad contrarrevolucionaria y traidora que el Estado reprime, la de los «nuevos burgueses... y otros elementos reaccionarios», alusión al Grupo de Shanghai.

4. Respeto del principio de legalidad socialista. Dentro del movimiento de critica al «derecho burgués», la breve Constitución de 1975 intentaba reducir la función del derecho en la sociedad, conservar sólo un "mínimun» de normas jurídicas y, en definitiva, prescindir del principio de legalidad (19). La Constitución de 1978, al contrario, coherente con la declaración del carácter beneficioso y protector del desarrollo de las fuerzas productivas que tiene el "derecho burgués», recupera el principio de legalidad presente en el texto de 1954. Ye Chieng-Ying, en el Informe sobre la reforma de la Constitución, defiende este principio en un apartado especial del discurso bajo el epígrafe "Acerca de la aplicación de la Constitución», que constituye una auténtica innovación (20). El respeto de la legalidad se traduce en las nuevas funciones acordadas a la APN y Asambleas Populares Locales - supervisar el cumplimiento de la Constitución (arts. 22,3 y 36)—, en el deber de observancia de la Ley Fundamental y demás leyes impuesto a funcionarios y ciudadanos (arts. 16 y 56), o en la restauración de una institución típica de los Estados socialistas, la Procuratura o Fiscalia Popular (art. 43).

5. Modernización de las fuerzas armadas. Persistiendo la dirección del P.C.Ch., sobre las fuerzas armadas y la unión personal entre presidente del comité central del P.C.Ch., y comandante en jefe del ejército, el art. 19 parece deparar un tratamiento ligeramente desigual al Ejército Popular de Liberación y a la milicia popular, y destaca la nacesidad de «modernizar el ejército». Del artículo 19 ha desaparecido, además, la consideración de EPL como «destacamento de combate y, a la vez, destacamento de trabajo y destacamento de producción», considerándolo ahora exclusivamente "pilar de la dictadura del proletariado", lo que puede resultar un indicio de la tendencia a "profesionalizar» el EPL.

(19) Cfr. P. Biscaretti, op. cit., págs. 23, 29 y ss.

(20) Documentos de la $V$ Asamblea..., op. cit., págs. 215 y ss. En él se afirma: «El fortalecimiento de la legalidad socialista responde a las necesidades de la dictadura del proletariado y a las del pueblo y concuerda por completo con los intereses fundamentales de las grandes masas populares. La legalidad socialista representa un freno y una atadura para aquellos que contravienen la ley (...) Si queremos conducir nuestro pais a un gran orden, necesitamos estatutos destinados a este objetivo. La nueva Constitución son (estos) estatutos. (...) Una vez aprobada, hay que asegurar su aplicación completa tanto en letra como en espiritu. No es admisible que la viole ninguna persona, sea quien fuere." 
C. El Capítulo II, dedicado a regular la «Estructura del Estado», ha sido objeto de importantes modificaciones:

1. Reforzamiento de los poderes de la Asamblea Popular Nacional. El art. 16 de la Constitución de 1975 situaba la APN «bajo la dirección del P.C.Ch.». La nueva redacción (art. 20), que sigue definiendo la APN como el órgano supremo del poder del Estado, al omitir dicha frase, suprime la dependencia jerárquica de la Asamblea respecto del Partido. El nuevo articulado constitucionaliza el sufragio indirecto - los diputados (art. 21) son elegidos por las asambleas populares y por el EPL- y desaparece la cooptación (art. 16,2 de la Constitución de 1975) que permitía «invitar como diputados a cierto número de personalidades patriotas" a las sesiones de la APN. Los diputados no están vinculados por mandato representativo, pues quedan bajo la "supervisión de las entidades que los eligieron", que los pueden revocar o sustituir en cualquier momento (art. 29, reproducción del art. 38 de la Constitución de 1954); y disponen del derecho de interpelar al Consejo de Estado y sus comisiones, al Tribunal Supremo Popular, Procuratura ministerios, estando obligados estos organismos a dar respuesta (art. 28), derecho existente ya en la Constitución de 1954 (art. 36), aunque entre los órganos objeto de interpelación no se incluía al Tribunal Popular Supremo ni a la Procuratura, como, por otro lado, sucede en la Ley Constitucional de la Federación Checoslovaca, de 27 de octubre de 1968 (art. 49), pero no en la Constitución soviética de 1977, cuyo art. 117 es muy similar al homólogo chino. La duración de la APN sigue siendo de cinco años, debiendo reunirse al menos una vez al año - precepto ya existente en las dos anteriores constituciones y constantemente vulnerado-, y previéndose explícitamente tanto la prórroga de la legislatura como la disolución anticipada. Nada se regula respecto a la organización interna, salvo la posibilidad de constituir "comisiones especiales según las necesidades» (21).

Las funciones de la APN (arts. 22 y 23) son considerablemente aumentadas en relación con la Constitución de 1975 (22). La mayor parte de las nuevas competencias atribuidas específicamente están recogidas de la Constitución de 1954 (arts. 27 y 28):

(21) La Constitución de 1978, como se ve, regula algunos de los «istitu tradizionali delle stituzioni parlamentari» que la lacónica Constitución de 1975 habia silenciado en relación con la de 1954, considerándolos residuos excesivamente vinculados al «derecho burgués». Cfr. P. Biscaretti, op. cit., pág. 61.

(22) La enumeración de competencias que realizaba el art. 17 no era considerada por TSIEN TCHE-HaO, La Chine.., op. cit., pág. 464 exhaustiva; lo mismo afirma (pág. 467) de las competencias del Comité Permanente de la APN. En todo caso es significativo el menosprecio en dicha Constitución de la técnica jurídica. 
- supervisar la aplicación de la Constitución y las leyes;

- nombrar a los miembros del Consejo de Estado: Al Primer Ministro, a propuesta del Comité Central del P.C.Ch.; al resto, a propuesta del Primer Ministro, y no del P.C.Ch., como en la Constitución anterior;

- elegir al Presidente del Tribunal Popular Supremo, competencia del Comité Permanente dé la APN en la Constitución de 1975, y al Fiscal General de la Procuratura;

- ratificar la división administrativa de las provincias, las regiones autónomas y los municipios directamente subordinados al Poder Central

- decidir sobre las cuestiones de la guerra y la paz;

- revocar a los integrantes del Consejo de Estado, que precisaba en 1975 la propuesta previa del Comité Central del PCCh, al presidente del Tribunal Supremo y al Fiscal General.

2. El Comité Permanente, jefatura de Estado colegiada y delegación permanente de la APN, equivalente al Presidium soviético, también ve modificada su composición interna, su estatus institucional en relación a la APN y sus competencias, en una nueva regulación muy dependiente del articulado de la Constitución de 1954 (arts. 30-33). En su composición figura de nuevo un Secretario general -órgano elegido en 1975, pero no constitucionalizado (23). El Comité Permanente, cuyos integrantes son elegidos por la APN, depende horizontalmente de la Asamblea, ante la que «responde y rinde cuentas de su gestión", aspecto silenciado en el anterior texto constitucional. Al igual que el órgano supremo del poder estatal, puede constituir comisiones especiales.

Las funciones nuevas que la Constitución le atribuye - algunas idénticas a las del Presidium del Soviet Supremo de la URSS - son:

- dirigir las elecciones de diputados de la APN;

- interpretar la Constitución;

- supervisar la gestión del Consejo de Estado, del TPS y Procuratura;

- modificar o revocar las disposiciones inadecuadas de los órganos del poder del estado en las provincias, regiones autónomas y municipios directamente subordinados al Poder Central;

- en el período entre sesiones de la APN, nombrar y revocar, en casos individuales, los integrantes del Consejo de Estado a pro-

(23) Cfr. Paolo Biscaretti, op. cit., págs. 65-66. 
puesta del Primer ministro; declarar el estado de guerra en caso de agresión armada;

- nombrar y sustituir los vicepresidentes del TPS y adjuntos de la Procuratura; y derogación (sic) de tratados;

- instituir títulos honoríficos del Estado, acordar su concesión;

- ratificar los estatutos de autonomía de las áreas nacionales;

- decidir la amnistía especial.

La Constitución confirma la supresión de la jefatura de Estado unipersonal realizada en 1975, al transferir la mayor parte de sus competencias a este órgano colegiado, el Comité Permanente de la APN. Pero hay que poner de relieve que no todas las competencias de una jefatura del Estado son ejercidas por el Comité, ya que algunas - ratificación de tratados, recepción de credenciales de representantes diplomáticos, etc., en definitiva, las funciones simbólicas o representativas (art. 26)- son transferidas el Presidente del Comité Permanente, en una situación que recuerda la de órganos homólogos en Bulgaria (art. 96 de su Constitución) o de la República Democrática Alemana (arts. 69 y 71 de la Constitución).

3. El Consejo de Estado, definido «Gobierno Popular Central, órgano ejecutivo supremo del poder del Estado y órgano administrativo supremo del Estado» (art. 30), también amplía su esfera de competencias con algunas de las conferidas al Consejo Político en la Constitución de 1954 (art. 49): iniciativa legislativa, defiende los intereses del Estado, mantiene el orden público, protege los derechos de los ciudadanos, ratifica ciertas divisiones administrativas de nivel inferior y designa y depone funcionarios. En un caso, se restringen sus competencias, ya que si en la Constitución de 1975 (art. 20) se le atribuía la dirección unificada de todos los organismos locales del Estado, ahora sólo dirige los tipo administrativo, es decir, los comités revolucionarios (art. 33).

4. Constitucionalización de la división administrativa de la RPCh, recogiéndola de la Constitución de 1954 (art. 53), si bien con la diferencia de incluir la comuna popular en lugar del cantón. Este artículo tiene indirectamente, a nuestro juicio, una importancia decisiva, pues establece la división territorial del Estado, base de organización de los respectivos órganos locales del poder y de la administración del Estado. En otras palabras, el poder estatal se constituye sobre ámbitos territoriales y no sobre otras entidades, tales las unidades de producción, los centros docentes, etc. La transcendencia de definir los órganos locales del poder y de la administración del Estado -Asambleas populares locales y comités revolucionarios- en relación a 
ámbitos territoriales supone la eliminación radical de instituciones surgidas de la Revolución Cultural, los Comités revolucionarios, de toda instancia que no sea estrictamente territorial, lo que implica concebir las unidades de producción, los centros educativos, los mismos organismos del Estado, etc., como ámbitos no políticos, negarles su condición de sede del poder estatal, en un proceso similar al efectuado con las comunas populares. De esta manera, se suspende en la práctica la aplicación del punto 9 de la Decisión del Comité Central del P.C.Ch. sobre la Gran Revolución Cultural Proletaria, de 8 de agosto de 1966. Esta decisión de abolir los comités revolucionarios de ciertas áreas de la organización social, y justificada mediante el trámite de concebirlos como órganos de institucionalización de un poder estatal constituido sobre áreas territoriales, no está constitucionalizada expresa, sino implícitamente: se infiere del articulado, y ha sido formulada por Hua Kuo-Feng en el Informe sobre la labor del Gobierno ante la $A P N$ :

«Las fábricas, brigadas de producción, centros docentes, comercios, organismos del Estado y otras empresas e instituciones. a excepción de aquellas empresas fabriles y mineras que fusionan en sí el Poder de base y la administración económica, no son órganos del Poder de instancia alguna y, por lo tanto, no instituirán comités revolucionarios como lo hacían hacian antes, sino que deben, en cambio, implantar el sistema de división del trabajo y responsabilidad personal del director, jefe, rector o gerente, según sea el caso, bajo la dirección de los respectivos comités del Parti do» (24).

5. Como órganos locales del poder del Estado y de la administración estatal, las Asambleas populares locales y comités revolucionarios -considerados los últimos simultáneamente gobiernos populares y órganos ejecutivos de las asambleas respectivas, por lo que acumulan las funciones que en

(24) Documentos de la V APN..., op. cit., págs. 89-90. ¿Se'trata de despolitizar y disciplinar ciertos núcleos organizativos considerados esenciales para el proceso productivo? La Constitución de 1975 no parece, a nuestro juicio, aludir explícitamente a los comités revolucionarios de fábrica, escuela, etc., sino -como la de 1978- a los comités revolucionarios, órganos permanentes de las asambleas populares locales; pero el silencio sobre la división territorial y la ausencia de declaraciones explícias, permiten deducir la vigencia de dichos organismos, situación no sostenible ya respecto al orden jurídico instaurado con la nueva Constitución. Sobre los comités revolucionarios, en sus dos acepciones, cfr. Tsien Tche-Hau, La Chine, op. cit., págs. 472 y ss. PaOlo BisCaretTl, op. cit., págs. 68 y ss. no los diferencia. 
el orden central corresponde al Comité Permanente de la APN y al Consejo de Estado se constituyen en los ámbitos territoriales definidos en el art. 33. Los correspondientes a la comuna popular (art. 34,2) son definidos como "organización del Poder de base y también organismos dirigentes de la economía colectivan, caracteres que el artículo 7 de la Constitución de 1975 predicaba de las propias comunas populares y no de sus órganos.

El sistema electivo de las asambleas populares locales es indirecto, y los diputados tienen idéntico derecho de interpelación sobre los organismos simétricos que los de la APN. los comités revolucionarios son elegidos, y revocados, por las respectivas asambleas populares, estando articulados entre sí por el principio de doble dependencia (art. 37,2), y en consecuencia, rinden cuentas de su gestión ante las asambleas que los eligen y ante los órganos administrativos jerárquicamente superiores. El Consejo de Estado dirige unificadamente todos los comités revolucionarios.

La regulación de ambos tipos de institución también introduce modificaciones de relevancia. Las Asambleas populares locales ven ampliada sus competencias: aseguran la observancia de la Constitución; planifican la construcción económica y cultural, y las obras públicas de las localidades; protegen los bienes públicos; garantizan la igualdad de derechos de las minorías nacionales; mantienen el orden público -y no el orden revolucionario, como afirmaba el texto de 1975-; las de distrito y niveles superiores, nombran y revocan los presidentes de los tribunales fiscales generales de la procuratura correspondientes; $y$, lo que constituye una importante novedad, adoptan disposiciones dentro de los límites de la competencia que la ley les confiere (art. 36, que recoge parte del contenido de los arts. 58 y 60 de la Constitución de 1954).

Los comités revolucionarios experimentan una doble limitación:

a) De competencias, ya que a tenor de la Constitución de 1975 (art. 23 en relación con el 25), los comités revolucionarios tenían idénticos poderes que las asambleas populares locales respectivas, y nombraban, además, a los presidentes de los tribunales populares. En la Constitución de 1978, sus funciones se limitan y se especializan, como corresponde a su carácter de órgano de gobierno y administración, y de ejecución de las APL: ajecuta sus decisiones y las de los organismos del Estado de tipo administrativo, dicta disposiciones y nombra y destituye funcionarios.

b) Del campo de implantación, pues, según se refirió, al redefinir las áreas de poder como áreas territoriales, se eliminan los comités de las unidades de producción, escuelas, etc., e incluso de subdivisiones 
territoriales - prefecturas no autónomas-, en las que se constituyen oficinas administrativas delegadas.

6. En cuanto al tratamiento que reciben las distintas nacionalidades, la nueva Constitución, tal como hacía la de 1975, garantiza la autonomía nacional en regiones, prefecturas y distritos, cuyos órganos son las asambleas populares y comités revolucionarios, sujetos a las prescripciones ya enunciadas. Sin embargo, se introducen dos modificaciones de interés, tomadas de la Constitución de 1954 (arts. 68 y 70): se garantiza la representación de todas las minorías nacionales en las zonas donde habiten más de una (art. 38,3), y se confiere a los órganos autónomos la posibilidad de elaborar sus estatutos de autonomía, que deberán ser aprobados por el Comité Permanente de la APN. Se advierte, en general, una mayor explicitación de la necesidad de garantizar las minorías nacionales, sus derechos, como en la previsión del uso de la lengua o lenguas de las nacionalidades correspondientes en los organismos oficiales.

7. La organización judicial y fiscalizadora se estructura con importantes novedades, tomadas en su mayor parte de la Constitución de 1954 (arts. 73 y ss).

a) La organización judicial se compone de un Tribunal Popular Supremo (TPS) y una serie jerárquica de tribunales populares locales y especiales. Los Tribunales superiores supervisan la actuación de los inferiores, y todos son supervisados, en última instancia, por el TPS, modificación con respecto a la Constitución de 1975 que significa la reintroducción del principio de control de legitimidad, al tiempo que se conserva el control político, ya que todos los tribunales populares responden de su actuación ante las asambleas populares respectivas, ya sea la APN o las locales (art. 42), sistema de articulación de doble dependencia. Nada se dice de la duración del mandato, ni de las peculiaridades de los tribunales especiales.

Del articulado desaparece la alusión explícita a la «línea de masas» en la aplicación de la justicia (25), y se reintroducen la institución de los asesores populares, la publicidad del proceso y el derecho de defensa del acusado.

b) Como órganos de fiscalización se restaura la Procuratura, abolida en la Constitución de 1975 en beneficio de los organismos de seguridad pública, que la habían absorbido hasta el punto de ocupar los mismos

(25) "Linea de masas» que por su vaguedad fue objeto de severos críticas por P. BiscaretTi, op. cit., págs. 78-80. Para Tsien TChe-Hao, La Chine, op. cit., págs. 497 y ss. no era un concepto tan vago como parecia al profesor italiano. 
edificios (26). La restauración de la Procuratura o Fiscalía Popular es consecuencia de la revalorización del principio de legalidad. La procuratura se organiza en una Fiscalía Popular Suprema, nombrada por la APN, que controla todos los órganos dependientes del Consejo de Estado, los organismos locales, funcionarios y ciudadanos, y asegura la observancia de la Constitución y de las leyes, y una serie jerárquica de físcalías populares locales, que dependen, y rinden cuenta, de los respectivos órganos locales del poder del Estado. En este sentido, hay una notable diferencia con la Constitución soviética de 1977, y no sólo en el procedimiento de designación, pues en la URSS se establece la total independencia de los órganos de la Procuratura respecto de los órganos locales, y en menor medida, de la propia Constitución china de 1954, que los hacía independientes de los órganos administrativos locales. La Fiscalía Popular Suprema y las locales se vinculan y supervisan entre sí, en razón de su jerarquía. Nada dice la Constitución de la duración del mandato de la Procuratura, y se omite en este apartado del capitulo II toda referencia a los organismos de la seguridad del Estado.

D. El-Capítulo III, dedicado a los «Derechos y deberes fundamentales de los ciudadanos", es más extenso, y está mejor sistematizado, que el de la Constitución de 1975, aunque son pocas las diferencias de contenido: se introduce el derecho a la libre investigación científica, la libertad cultural (art. 52), la declaración de que el Estado estimula la planificación de la natalidad y de que el matrimonio se basa en la libre determinación del hombre y la mujer (art. 53). Entre los deberes, se añade el de salvaguardar la unidad de la patria y la unidad de las diversas nacionalidades del país el de cuidar y proteger los bienes públicos, observar la disciplina laboral y el orden público, respetar la moral socialista y los secretos del Estado (arts. 56 y 57). Finalmente, la Constitución declara que el Estado presta atención especial a los jóvenes y adolescentes, y a las condiciones de vida de los militares revolucionarios inválidos y familias de los «mártires revolucionarios».

(26) Cfr. JoHN GaRdner, The Chinese Constitution of 1975, en Government and Opposition, vol. 11, n. 2 , spring 1976, pág. 215. 


\section{LAS REFORMAS DE LOS ESTATUTOS DEL PCCh Y DE LA CONFERENCIA CONSULTIVA POLITICA DEL PUEBLO CHINO (27)}

El examen del nuevo orden constitucional quedaria incompleto sin una referencia, aunque deliberadamente sumaria, a los nuevos estatutos del P.C.Ch. y de la Conferencia Consultiva Política del Pueblo Chino (CCPPCh).

A. Diversos autores señalaron, refíriéndose a la Constitución de 1975, la «absoluta preemiencia del P.C.Ch. su carácter supraestatal, o la determinación de reconocer «de iure» el estatus que el partido comunista ostentaba "de facto» (28). La constitución de 1978 ha atenuado esa absoluta preeminencia - Gardner quizás dijera que el texto ha disminuido su "grado de sinceridad», ha descendido en su "nivel de confianza»-: pese a las referencias del Preámbulo, $\mathrm{y}$ al tenor literal del art. 2 de la Constitución - «El P.C.Ch. es el núcleo dirigente de todo el pueblo chino. La clase obrera ejerce su dirección sobre el Estado a través de su destacamento de vanguardia, el Partido Comunista de China», es obvio que las competencias del P.C.Ch. han disminuido, puesto que ya no dirige la APN, ni propone a los ministros, con excepción del Primer Ministro; subsiste, es cierto, la unión personal entre presidencia del partido y jefatura de las fuerzas armadas, y habría que añadir, en la práctica, la acumulación de todos esos cargos, y el de Primer Ministro en la persona de Hua Kuo-Feng.

Si aun con las limitaciones enunciadas en relación a 1975, la constitucionalización vigente del P.C.Ch., - -y la situación real- es la que más acentúa su carácter de fuerza dirigente del Estado entre todas las Constituciones socialistas, es obvio, no obstante, el intento de distinguir, al menos formalmente, jurídicamente, la estructura del Estado y la del partido en la actualidad; aquélla estaría regulada en la Constitución; el Partido, la organización encargada de trazar las directrices políticas y dinamizar la sociedad, en sus estatutos.

Al cambio de Constitución, como ya sucedió con la de 1975, precede una reforma de los Estatutos del Partido. El problema, que se origina al confrontar ciertos artículos de los estatutos (art. 14, por ejemplo) con

(27) Los nuevos estatutos del P.C.Ch., en Undécimo..., op. cit., págs. 131-154. Los de la CCPPh, en Pekin Informa, n. ${ }^{\circ}$ 12, 29 de marzo de 1978, págs. 32-36.

(28) Cfr. P. Biscaretti op. cit., págs. 37-40; Manuel B. García Alvarez, Partido y Estado en las Constituciones socialistas, en Pedro de Vega (Editor, Teoria y práctica de los partidos políticos, Madrid, Edicusa, 1977, págs. 342-344.; J. GARDNER, op. cit., pág. 223; en menos medida, TTsien Tche-Hao, La Chine, op. cit., págs. 416-418. 
la Constitución, es, en definitiva, el del sistema de fuentes, el de la jerarquía normativa -si tiene sentido formularlo en el constitucionalismo chino-; problema insuficientemente analizado, y dificil, si no imposible, de resolver cuando nos encontramos ante una Constitución flexible y se ignora el tipo de norma, la forma jurídica de los estatutos del partido (29).

Los nuevos estatutos, aprobados en agosto de 1977, incluyen en el preámbulo referencias, antes inexistentes, al frente único revolucionario, a las tareas de construcción de las "cuatro modernizaciones", y matiza el debatido derecho a «ir contra la corriente», pues define su curso: se puede combatir "toda corriente que contravenga estos principios». En el articulado destacan:

1. La restauración (art. 4) del período de permanencia - un año- como candidato antes de pasar a la condición de afiliado, y durante el cual se carece de capacidad electoral activa y pasiva;

2. La previsión y regulación de un procedimiento disciplinario, con especialidad de fuero para los militares (art. 6), y la creación de comisiones de disciplina (art. 13);

3. Las referencias, entre las tareas de la organización, a la preocupación por la vida cultural y económica, inexistentes en los anteriores estatutos, más preocupados por la lucha ideológica;

4. La persistencia (art. 14) de la sumisión a la «dirección absoluta del partido... de los organismos del Estado, el Ejército Popular de Liberación y la milicia, los sindicatos obreros, la Liga de la Juventud Comunista, las asociaciones de campesinos pobres y campesinos medios inferiores, las federaciones de mujeres y las otras organizaciones revolucionarias de masas...", enumeración de la que, curiosamente, se omite -en comparación con los estatutos de 1973la mención a los Guardias Rojos y Pequeños Guardias Rojos». Esta sumisión de los organismos del Estado al P.C.Ch. origina problemas, ya formulạdos, al tener presente la nueva redacción del art. 20 de la Constitución.

B. Las constantes menciones del Frente Unico Revolucionario, de los partidos no comunistas y otras organizaciones de masas, y las novedosas referencias a la "dictadura democrática popular» han cristalizado en la revitalización de una institución, la CCPPh, órgano del FRENTE ÚNICO, cuyo Comité Nacional celebró sesiones paralelas a las de la APN, y

(29) La recuperación china del «derecho burgués» no llega a estos "refinamientos» técnicos. Sería más pertinente este tipo de planteamientos en el bloque soviético. 
sus miembros participaron como observadores en los trabajos constitucionales de la APN (30), y que constituyó la base de la organización gubernamental entre 1949 y 1954.

Los nuevos estatutos, aprobados en dichas sesiones, definen la CCPPCh como organización del Frente único, que ayuda «a los componentes de la burguesía nacional a aceptar la transformación socialista, en el cumplimiento de la orientación de coexistencia duradera y supervisión mutua entre el P.C.Ch. y los partidos democráticos». La Conferencia integra asociaciones y personas individuales, y se estructura en un Comité Nacional -que se renueva, como la APN, cada cinco años-y una serie de comités locales constituidos en las distintas áreas de la división administrativa.

Sus funciones pueden sistetizarse en:

1. Electorales; pese a no estar incluidas específicamente entre las tareas de la CCPPCh (art. 10), se deducen de otros artículos: "El comité Nacional y los comités locales de la CCPPCh efectúan consultas democráticas» (art. 8); "La CCPPCh lleva adelante la excelente tradición de consultas democráticas...» (art. 11).

2. Educativas y pedagógicas, tanto de difusión de las directrices políticas, como de adoctrinamiento de las distintas organizaciones sociales y de masas que la integran, en el pensamiento marxista-leninista-Mao Tsetung.

3. De colaboración en la política interna e internacional (31).

(30) Le Monde. Sélection hebdomadaire, n. ${ }^{0} 1530,23$ Fevrier au 1. ${ }^{\text {er }}$ Mars 1978, pág. 7.

(31) Sobre la CCPPh y los partidos no comunistas, véanse TsIEN TCHE-HAO, La Republique..., op. cit., págs. 159-167, 197-207 y 262-264, IDEM La Chine, op. cit., págs. 435-444. Entre nosotros, aunque más sumariamente, Manuel B. García Alvarez, Los partidos no comunistas en los Estados socialistas, en Colectivo, Estudios humanistas y juridicos, León, Colegio Universitario, 1977, págs. 140-142, passim. La persistencia de partidos políticos no comunistas no creo autorice, estrictamente hablando, a calificar la situación de multipartidismo, e incluso la tesis de J. WIART (sintetizada en The hegemonic party system in Poland, en Allardt y Rokkan ]Editores], Mass Politics, New York, The Free Pres, 1969, págs. 312-321) sobre el "partido hegemónico» como posible sistema de partidos debe utilizarse con suma cautela. El profesor Manuel García Pelayo, Supuestos estructurales de los sitemas politico-constitucionales de los países socialistas, en Burocradia y tecnocracia, Madrid, Alianza Universidad, 1974, págs. 153 y ss., refiriéndose a los Estados socialistas europeos parece considerarla imaplicable a Checoslovaquia; y en un sentido absolutamente restrictivo, véase el interesante G. SARTORI, Parties and party systems. A framework for analysis, vol. I, Cambridge University Press, 1976, págs. 230 y ss. 


\section{CONCLUSIONES}

Los cambios realizados en el sistema jurídico fundamental de la RPCh son un fiel reflejo de la tendencia ideológica del grupo «moderado» y de sus opciones políticas.

Los principios básicos reflejados en la Constitución y en la estructura institucional pueden formularse como:

A. Modernización económica y desarrollo acelerado de las fuerzas productivas. A él responden las declaraciones del preámbulo y las líneas programáticas de evolución que enuncia el articulado; sin él no se explican la confirmación del principio de distribución socialista, la constitucionalización de los incentivos materiales, la liberalización cultural, el fomento de la investigación científica y técnica, la introducción del principio de responsabilidad personal individual en la dirección de las unidades de producción y consiguiente supresión de los comités revolucionarios de estas entidades...

B. Revalorización del principio de legalidad socialista, recuperación del «derecho burgués» e introducción de la «democracia socialista». Principios que explican la restauración de la Procuratura, el reforzamiento de la APN y asambleas populares locales, la regulación de ciertas materias - derecho de interpelación de los diputados, organización interna de las cámaras-, la eliminación de la dependencia jerárquica del órgano supremo del poder del Estado respecto del P.C.Ch. la revitalización de la CCPPCh y otras organizaciones de masas, la mención continua del Frente Unico y de los partidos no comunistas.

C. Reforzamiento de la disciplina y la unidad tanto en el partido como en el conjunto del pueblo, del que son reflejo las reformas de los Estatutos del P.C.Ch. introduciendo procedimientos disciplinarios y comisiones de control, o las garantías explicitadas en relación con las minorías nacionales.

La Constitución de 1978 supone en resolución, la expresión jurídica de un orden político que consolida, de un lado, los logros alcanzados en las transformaciones económicas y las instituciones surgidas de la revolución cultural, aunque éstas matizadas y reformadas - constitucionalización de las clases de propiedad y de los sectores económicos, de los comités revolucionarios, de la dirección colegiada del Estado, del Estado de Dictadura del proletariado-, y que proyecta, de otro, la realización de una nueva etapa en el proceso de construcción del comunismo, nueva etapa que exige, es obvio, rectificaciones, y que justifica la recuperación de muchos de los contenidos de la Constitución de 1954, básicamente los relacionados con el «derecho burgués». 